\title{
TESTAMENTO VITAL: UMA ANÁLISE A PARTIR DO DIREITO ESTRANGEIRO E DE UM LEADING CASE BRASILEIRO
}

\section{Carlos Eduardo Silva e Souza}

Doutor em Direito pela Faculdade Autônoma de Direito de São Paulo. Mestre em Direito pela Universidade Federal de Mato Grosso. Professor Adjunto (dos Cursos de Graduação em Direito e Mestrado em Direito Agroambiental) da Faculdade de Direito da Universidade Federal de Mato Grosso. Coordenador de Pesquisa da Faculdade de Direito da Universidade Federal de Mato Grosso. Líder do Grupo de Pesquisa "Direito Civil Contemporâneo" da Faculdade de Direito da Universidade Federal de Mato Grosso. Advogado do Escritório Silva Neto e Souza Advogados. professorcarloseduardo@gmail.com

\section{Vladia Maria de Moura Soares Sanches}

Doutoranda em Direito pela Pontifícia Universidade Católica de São Paulo. Mestre em Direito pela Pontifícia Universidade Católica de São Paulo. Professora da Faculdade de Direito da Universidade de Cuiabá. Advogada.vss_adv34@hotmail.com

\section{Resumo}

O presente artigo objetiva estudar o instituto do testamento vital, isto é, a disposição de última vontade que envolve o bem mais sublime e importante do ser humano, isto é, a sua própria vida, quando envolvida uma circunstância de enfermidade ou gravo dano físico incurável, geradores de grande sofrimento físico. Nesse sentido, a ideia inicial é dirigida para a compreensão do próprio objeto pesquisado, isto é, do que vem a ser efetivamente testamento vital. Em seguida, são apresentadas as controvérsias que geram ao redor do objeto da presente pesquisa. Ao depois, o assunto é abordado sob a ótica do direito estrangeiro, apresentando-se especialmente os regramentos dos Estados Unidos da América, Canadá, União Europeia, Grã-Bretanha, Espanha, Portugal e Itália. Compreendido o testamento vital nessa múltipla perspectiva, a ideia direciona-se para a compreensão da temática em relação à capacidade humana de testar, quando se contrapóe o assunto com as disposições do próprio direito interno. Ao final, as ideias conclusivas são apresentadas de forma articulada, a fim de se evidenciar a essência das inquietaçóes que alimentaram o presente estudo. A investigação foi construída por meio da pesquisa bibliográfica, documental, além de outras fontes de informação escrita, a qual se serviu do método de abordagem qualitativo e do método dedutivo de análise de dados, com auxílio da técnica de observação direta intensiva e do método de procedimento monográfico. 


\section{Palavras-chave}

Testamento; Vida; Liberdade; Dignidade.

\section{Abstract}

This article aims to study the living will institute, that is, the last will that involves far more sublime and important human being, ie his own life when involved an infirmity of circumstance or record incurable physical damage of great physical suffering generators. In this sense, the initial idea is directed to understanding own researched object, that is, of what is to be effectively living will. Then they present the controversies they generate around the object of this research. By then, the issue is approached from the perspective of foreign law, appearing especially the specific regulations of the United States of America, Canada, European Union, Britain, Spain, Portugal and Italy. Understood the living will that multiple perspective, the idea directs to understanding the issue regarding the human ability to test, when contrasted it with the provisions of their own national law. Finally, the concluding ideas are presented in a coordinated way in order to show the essence of the concerns that have fueled this study. The research was built through bibliographic research, documentary, and other sources of written information, which has used the qualitative approach method and deductive method of data analysis, with the help of intensive direct observation technique and method monographic procedure.

\section{Key words}

Testament; Life; Freedom; Dignity.

\section{Introdução}

O chamado testamento vital diz respeito à disposição que alguém estabelece sobre o mais importante e sublime bem do ser humano: a própria vida. Considerando uma situação especialíssima, na qual o individuo perdeu sua capacidade de existência racional e autônoma em razão de enfermidade ou grave dano físico incurável, geradora de grandes sofrimentos.

Nesse contexto, impossível não reconhecer que o testamento vital tem importância sobremaneira destacada, especialmente ser considerada vertiginosa evolução tecnológica ligada à biologia e à medicina, nas suas mais variadas vertentes, que vem proporcionando cada dia mais e mais, meios técnicos de prolongamento da vida independentemente da possibilidade de sofrimento e angustia para o paciente e sua família.

Neste trabalho, procura-se enfocar as diversas formas de eutanásia e suas consequências como também os debates que surgem acerca do tấo controverso tema, e baseando 
em outros países, no direito comparado já tem como exemplos alguns meios do morrer dignamente, ou mesmo em um consultório americano onde o médico aconselha aos seus pacientes, dando-lhes o direito de conhecer e refletir sobre as diretrizes antecipadas, que são nada mais do que escolher como o paciente quer terminar a sua vida.

Com esse propósito, o trabalho é divido, portanto, em três partes: a primeira é dedicada a compreensão do próprio objeto de investigação, isto é, do testamento vital; a segunda, por sua vez, apresenta as controvérsias que giram ao redor do problema; a terceira, a seu turno, dedica-se a apreciar como o direito estrangeiro tem lidado com a questão do testamento vital; a quarta parte dedica-se a apreciar, segundo o entendimento do direito interno, a capacidade humana de testar; encerrando o trabalho, a quinta e última parte é voltada para análise de um leading case brasileiro que analisa especificamente o instituto do testamento vital.

A presente pesquisa é relevante, porque, enquanto se enfrenta dificuldades na compreensão e aceitação do testamento vital no Brasil, o tema encontra-se em estágio avançado em outros países, daí porque objetiva-se propor novas reflexóes a partir do presente trabalho.

O presente trabalho é fruto de uma investigação norteada por uma pesquisa bibliográfica, documental e de outras fontes de informação escrita, tendo-se servido do método de abordagem qualitativo, do método dedutivo de análise de dados, da técnica de observação direta intensiva e do método de procedimento monográfico.

\section{Compreendendo o Testamento Vital}

Eis o principal desafio ante o tema abordado no presente trabalho, o "morrer com dignidade" e respeitar a vontade daquele que se encontra já sem qualidade de vida e "nas mãos" de seus familiares/cuidadores. Existe a necessidade de se conceber o limiar de quando se deve atender os desejos do paciente e privilegiar àqueles que dizem que amam o ente agonizante, porém não permitem que se exercite seu direito de morrer.

Considerando essa singular situação na qual o indivíduo perdeu sua capacidade de existência racional e autônoma em razão de enfermidade ou grave dano físico incurável, geradora de grandes sofrimentos, é imperativo que se discorra sobre o importante instrumento de manifestação de vontade que é o chamado testamento vital. O Testamento Vital é utilizado para dispor, antecipadamente, sobre a assistência médica a ser prestada ao paciente terminal. O Testamento Vital ("testamento biológico, living will ou testament de vie”), paralelamente à figura do consentimento informado tem sido discutido em vários países. Merecem menção os ensinamentos de Maria Celeste Cordeiro ao apontar, como seu fundamento legal, o chamado direito à intimidade. A autonomia (do grego = faculdade 
para se auto-governar) como direito moral e legal, como dever: "a capacidade de autogoverno é a capacidade para pensar, sentir e emitir juízos sobre o que considera bom”.

O Testamento Vital visa influir sobre os médicos no sentido de uma determinada forma de tratamento ou, simplesmente, no sentido do não tratamento, como uma vontade do paciente que pode vir a estar incapacitado de manifestar sua vontade em razão da doença.

Roxana Cardoso Brasileiro Borges ${ }^{2}$ conceitua o Testamento Biológico como um documento em que a pessoa determina de forma escrita, o tipo de tratamento ou náo tratamento que deseja receber para a ocasiáo em que se encontrar doente, em estado incurável ou terminal, e incapaz de manifestar sua vontade.

Outra conceituação que merece menção é a de Adriana Carrera Calvo ${ }^{3}$ ao lecionar que Testamento Vital:

é um documento em que a pessoa determina, de forma escrita, que tipo de tratamento ou não tratamento deseja para a ocasião em que se encontrar doente, em estado incurável ou terminal, e incapaz de manifestar sua vontade. Não há regulamentação sobre o testamento vital no Brasil. Nos EUA, este documento tem valor legal, e o médico que desrespeitar as disposiçôes do testamento pode sofrer sançóes disciplinares.

Desse modo, pode-se entender que o testamento vital é um documento com diretrizes antecipadas, que uma pessoa realiza em uma situação de lucidez mental para que seja levado em conta quando, por causa de uma doença, em condição física ou mental incurável ou irreversível, e sem expectativas de cura ou já não seja possível expressar sua vontade. O que se assegura através destes documentos é a “morte digna”, no que se refere à assistência e ao tratamento médico a que será submetido um paciente.

As instruçóes destes testamentos, no mais das vezes, aplicam-se sob uma condição terminal, sob um estado permanente de inconsciência ou um dano cerebral irreversível que, além da consciência, não possibilite que a pessoa recupere a capacidade para tomar decisóes e expressar seus desejos futuros. Eis quando o testamento vital deve gerar seus efeitos, porquanto estabelecerá o tratamento a ser aplicado, os limites às medidas necessárias para manter o conforto, não se excetuando os que podem ocorrer como conseqüência da suspensão ou interrupção do tratamento.

1 CORDEIRO, Maria Celste apud PESSINI, L. Distanásia. Até quando prolongar a vida? São Paulo: Centro Universitário São Camilo e Ediçôes Loyola, 2001, p. 65.

2 BORGES, Roxana Cardoso Brasileiro. Direito de morrer dignamente: eutanásia, ortotanásia, consentimento informado, testamento vital, análise constitucional e penal e direito comparado. In: SANTOS, Maria Celeste Cordeiro Leite dos (org.). Biodireito: ciência da vida, os novos desafios. São Paulo: RT, 2001. p. 32.

3 CALVO, Adriana Carrera apud SANTOS, Maria Celeste Cordeiro Leite dos (org.). Biodireito: ciência da vida, os novos desafios. São Paulo: RT, 2001. p. 46. 
A primeira menção a possibilidade jurídica de tal instrumento ocorreu em 1967, quando a Sociedade Americana para Eutanásia propôs o testamento vital (living will) como documentos de cuidados antecipados, pelo qual os indivíduos poderiam registrar sua vontade quanto a intervençóes médicas para manutenção da vida. Porém, admite-se que efetivamente passou a existir em 1969, pelas mãos de Luis Kutner, advogado de Chicago, e se inscreve no tipo de documentos enquadrados, genericamente, sob a denominação de consentimento informado.

Luis Kutner sugeriu um documento no qual o próprio indivíduo declarava que se entrasse em estado vegetativo, com impossibilidade incontestável de se recuperarem suas capacidades físicas e mentais, deveriam ser suspensos os tratamentos médicos. Para tanto, tal documento deveria atender a quatro finalidades: primeira, em processos judiciais, a necessidade de se ter em conta a diferença entre homicídio privilegiado por relevante valor moral, a compaixão, e o homicídio qualificado por motivo torpe; segunda, a necessidade legal de permitir, ao paciente, o direito de morrer por sua vontade; a terceira, a necessidade de o paciente expressar seu desejo de morrer, ainda que incapaz de dar seu consentimento na ocasião; quarta, para satisfazer às três primeiras finalidades, dever-se-ia dar, ao paciente, garantias necessárias de que sua vontade seria cumprida. ${ }^{4}$

Entretanto, havia apenas tentativas, as quais acabaram fracassadas, e somente em 1972, nos EUA, que este documento teve valor legal, tendo surgido com o Natural Death Act, na Califórnia. Assim, o testamento vital passou a ser um documento comum a ser incorporado às leis de morte natural (Natural Death Acts).

Em 1976, com a promulgação, na Califórnia, da primeira lei sobre morte natural, vigente até 1991, quando entrou em vigor a lei federal de autodeterminação do paciente, onde definitivamente obrigava o sistema hospitalar a respeitar o documento. Nesse período, a opiniáo pública foi mobilizada por processos judiciais de grande repercussão, como por exemplo: o Caso Quinlan, de 1976, o Caso Conroy, de 1985, e o Caso Cruzan, de 1990, cujo objeto era a retirada de tratamentos vitais. Esses casos fizeram com que muitas pessoas temessem ficar presas a tratamentos similares aos impostos àqueles pacientes, com a Justiça exigindo, ao final de suas vidas, provas das preferências prévias de cada um. ${ }^{5}$

Em 1995, a Associação Médica Britânica em conjunto com a Comissão Legislativa do Governo Inglês produziu um código de prática para o documento de vontades antecipadas.

4 KUTNER apud RIBEIRO, Diaulas Costa. Suspensáo de esforço terapêutico. Cadernos de direito clínico. Faculdade de Ciências Jurídicas do Planalto Central. Ano I, número 1, Out. 2005. Brasília. p. 17.

5 RIBEIRO, Diaulas Costa. Suspensão de esforço terapêutico. Cadernos de direito clínico. Faculdade de Ciências Jurídicas do Planalto Central. Ano I, número 1, Out. 2005. Brasília. p. 18 
O governo do Reino Unido determinou que a capacidade mental fosse o requisito indispensável para a confecção de um documento de vontades antecipadas. ${ }^{6}$

Ante a atual capacidade das ciências médicas em realizar prognósticos eficazes, pretende-se ampliar as diretivas antecipadas a quaisquer enfermos em situaçóes clínicas potenciais. Desse modo, pode o paciente não só adotar determinado comportamento, mas recusar, ou optarem positivamente por um tratamento, diante do prognóstico que tem ciência. No terceiro período, as diretivas passaram a ser contempladas como uma mera extensão doutrinária do consentimento informado para a escolha de tratamentos médicos, sendo que, no Brasil, tal instituto não possui previsão legal.

Portanto, o testamento vital é um documento com diretrizes antecipadas, que uma pessoa realiza em uma situação de lucidez mental para que seja levado em conta quando, por causa de uma doença, em condiçáo física ou mental incurável ou irreversível, e sem expectativas de cura, já não seja possível expressar sua vontade.

\section{Um Tema que traz Controvérsias}

Muitas são as opinióes, convicções, os adeptos e os detratores dos testamentos vitais. A discussão pela validade, a ética e a necessidade de uma legislação para a existência e a aceitação ou náo de um testamento vital, é um tema a ser resolvido em vários países.

Na Argentina, desde a sociedade até o legislativo, a resposta para o tema "morte digna” não tem sido concreta, nem definitiva. O tema chegou a ser tratado pelo Congresso Nacional Argentino, onde um projeto de lei obteve uma média sanção, entretanto, não houve continuidade.

Existem algumas organizaçóes, entre elas a chamada Niketana, presidida pelo Dr. Hugo Dopaso - médico que escreveu livros como El Buen Morir - que sustenta a necessidade de respeitar os desejos individuais relativos aos direitos das pessoas, nos últimos momentos de suas vidas. Existem correntes religiosas que também entendem que todo paciente em estado terminal deve ter por direito, acompanhamento e a dignidade.

Entretanto, também existem muitas posições que entendem que ninguém pode decidir sobre a vida ou a morte e menos ainda saber, em muitos casos, as possibilidades de uma pessoa frente a uma doença, por mais grave que esta seja.

Atualmente, muita pessoa de forma individual ou coletivamente tem redigido e assinado seus manifestos e comunicado às suas famílias, às pessoas mais próximas ou às

6 KUTNER apud RIBEIRO, Diaulas Costa. Suspensão de esforço terapêutico. Cadernos de direito clínico. Faculdade de Ciências Jurídicas do Planalto Central. Ano I, número 1, Out. 2005. Brasília. p. 17 . 
instituiçóes que sustentam este direito. Além do mais, quando for o caso, o testamento não representará um desejo legalmente garantido. As pessoas envolvidas - médicos, familiares e autoridades - deverão decidir as possibilidades de sua aceitação ou não.

Filosoficamente, discute-se a transcendência e os possíveis conceitos no contexto de uma distinção entre a morte e falecimento, sobre o significado da vida ou continuação da mesma sem "qualidade", ou do prolongamento do processo de morte. O debate estabelecido é vinculado ao conceito de eutanásia, tendo por este âmbito quem diferencie entre eutanásia ativa e eutanásia passiva. A Eutanásia ativa consiste na ação de interromper de maneira artificial, a vida de um paciente que não morreria de maneira natural.

Eutanásia passiva corresponde à morte pela não aplicação de tratamentos médicos ante uma patologia que, por náo ser assistida, provocaria a morte do paciente. Aqueles que sustentam a validade e necessidade de respeitar um testamento vital consideram a eutanásia passiva não é mais que deixar que a natureza haja no que a medicina não pode remediar.

\section{0 Testamento Vital e o Direito Estrangeiro}

\subsection{Estados Unidos da América}

Nos Estados Unidos da América, desde 1991, por meio do Patient Self-Determination Act, compeliram todos os hospitais, agências de saúde e hospices do país a prover aos paciente admitidos que informem sobre suas decisóes pessoais e os tratamentos que desejam ou não receber como cuidados. Essa lei também prevê que serão respeitadas as diretrizes antecipadas e informadas pelo paciente. Atualmente, todos os Estados Americanos possuem estatutos formalizados para o Testamento Vital, que teve início na Califórnia, no ano de 1976, com o Natural Death Act. No Estado do Óregon, em 1990, os médicos criaram um documento em que se expressavam os desejos dos pacientes, chamado de Physicians Order for Life-Sustaining Treatment - POLST, utilizado em pacientes com um ano ou menos de expectativa de vida, questionando-os sobre o que esperavam da Instituição de tratamentos específicos para suporte de vida. Alguns Estados estipulam um formulário básico simplificado de diretrizes para aqueles indivíduos interessados em expressar seus desejos previamente para quando tornarem-se incompetentes em tomar suas próprias decisôes?

Os estatutos disponibilizam desde uma declaração simples que discriminam quais os suportes de vida são acolhidos ou não pelo declarante como ressuscitação cardiopulmonar,

7 BORGES, R. C. B. Direito de morrer dignamente: eutanásia, ortotanásia, consentimento informado, testamento vital, análise constitucional e penal e direito comparado. In: Santos MCCL (org.). Biodireito: ciência da vida, os novos desafios. Disponível em: <http://jus2.uol.com.br/doutrina/ texto.asp?id=7571. Acesso em: 10 out. 2014 . 
ventilação mecânica por respirador, terapia de eletro-choque, diálise renal, quimioterapia, transfusão de sangue e hemoderivados, instalação de cateteres, atos cirúrgicos necessários para o conforto e alívio da dor, antibioticoterapia, nutrição e hidratação até informaçôes específicas para cuidados em patologias como câncer, infecção por HIV, doenças degenerativas do sistema nervoso central.

Os estatutos exigem que o declarante seja capaz e maior de 18 anos. $\mathrm{O}$ registro pode ser feito em órgão estatal na presença de testemunhas maiores de 18 anos que assinaram o documento de vontades antecipadas. O declarante deve informar expressamente que é um desejo pessoal; que não está sendo influenciado ou coagido; que não se trata de uma fraude ou constrangimento e que sua assinatura é voluntária e está garantida por lei. Da mesma maneira, ratifica, nesses termos, que a família, os médicos assistentes e todos que se preocupam com sua saúde estão absolvidos legalmente, por terem seguido as instruçôes declaradas. Existe a previsão da nomeação de um "agente responsável legal" que possuirá poderes determinados pelo declarante, e só atuará quando o médico assistente comunicar que o declarante não está mais capaz de tomar decisões. O sigilo das decisões é partilhado somente com as pessoas de confiança do declarante. $\mathrm{O}$ médico assistente e os profissionais de enfermagem não podem ser nomeados agentes pelo declarante. $\mathrm{O}$ agente nomeado deverá portar a cópia do Testamento Vital quando for notificado que o declarante perdeu sua capacidade de decisão ou encontra-se inconsciente. $\mathrm{O}$ documento pode ser cancelado a qualquer momento. Recomenda-se que ele seja revisto periodicamente. O agente pode ser destituído oralmente pelo declarante se assim for desejado. Existe também a possibilidade de se fazer um registro eletrônico das diretrizes antecipadas - dentre outras maneiras, como as que nomeiam advogados especializados - que é disponibilizado 24 horas por dia em todo o país cujo acesso é concedido mediante a informação de senha. Este serviço pode ser acessado através de um membro provedor de cuidados ou de uma comunidade associada. ${ }^{8} \mathrm{O}$ documento poderá prever outras decisóes - concernentes à boa prática médica - que se queiram deixar registradas como, por exemplo, a previsão da doação de órgãos. $\mathrm{O}$ direito a fazer escolhas com relação aos cuidados de saúde, por meio de um documento de diretrizes antecipadas, tem garantia plena concedida pela Corte Suprema Americana, que protege, portanto, a dignidade do declarante.

\subsection{Canadá}

Segundo o Centro de Bioética da Universidade de Toronto, o Testamento Vital faz parte de um processo chamado plano para cuidados antecipados em que se faz a

8 BBC. A Short History of Important Events; Disponível em: <http://www.bbc.co.uk/religion/ethics/ euthanasia/overview/livingwills_print.html. Acesso em: 13 out. 2014. 
comunicação entre os pacientes e seus entes queridos sobre questôes relacionadas à sua saúde quando ocorrerem diagnósticos em que não existam esperanças de recuperação. ${ }^{9}$

A nomeação de um agente pode vir complementar o Testamento Vital. Ele poderá tomar decisóes caso o declarante determine.

A Associação Médica Canadense endossa a política de suporte ao Testamento Biológico, bem como muitos médicos autônomos também são favoráveis. Algumas províncias canadenses têm legislaçóes especiais. $\mathrm{O}$ requerimento deve ser feito por agência institucional do governo. As províncias de Alberta, Manitoba, Newfoudland, Nova Scotia, Quebec e Saskatchewan legalizaram o registro do Testamento Vital. O Testamento Biológico tem nomes e previsôes legais diferentes nas diversas províncias canadenses.

O Centro de Bioética da Universidade de Toronto propôs um formulário que foi desenvolvido pelo professor Peter Singer e atualmente é utilizado nas províncias de Alberta, Prince Edward Island, Saskatchewan, Nova Scotia, Newfoundland, New Brunswick, Manitoba e Ontário. O formulário contém um anexo que informa detalhadamente as situaçóes em que se requerem cuidados de saúde especializados.

Por exemplo, diante de uma pneumonia que evolua para uma insuficiência respiratória será realizado um procedimento de ventilação artificial considerado na tábua do formulário. Situações clínicas diagnosticadas, como derrame cerebral, demência, coma permanente vegetativo, e doenças excluídas de proposta terapêutica e sem expectativa de cura, como certos tipos de câncer, são abordadas em formulários especializados e ajuda a decidir o suporte de apoio vital indicado para cada caso. O médico assistente poderá, nessas situaçóes, esclarecer as dúvidas sobre a doença e os protocolos de tratamento. Outras decisôes pessoais podem constar no documento como, por exemplo, o local onde o declarante gostaria de receber os cuidados. Em caso de não ser possível receber o tratamento no domicílio, o paciente pode declarar se aceita ou não ser transferido para um hospício. Cuidado com a alimentação, higiene, tipo de vestimenta também podem ser incluídos no testamento como decisóes e desejos pessoais. O requerente decidirá sobre uma tábua de situaçóes colocadas, optando e escolhendo as palavras: sim, não, não decidido e tentar.

\subsection{União Européia}

O parlamento europeu aprovou em 1994 a declaração sobre a promoção dos Direitos dos Pacientes que foi ratificada com o Convênio do Conselho Europeu sobre os direitos do Homem e da Biomedicina no ano de 1997.

9 CENTRAL NOTTINGHAMSHIRE HEALTH COMMUNiTY. Disponível em:<http://www. nimhe.csip.org.uk/silo/files/livingwillspdf.pdf. Acesso em: 23 set. 2014. 
Nos termos do artigo $9^{\circ}$ do indigitado Convênio serão levados em consideração os desejos expressados anteriormente com respeito a uma intervenção médica no momento em que o paciente não se encontre em situação de expressar sua vontade.

\subsection{Grã-Bretanha}

Em abril de 1995, a Associação Médica Britânica (BMA) publicou um código de prática de tratamentos médicos mediante as declaraçóes antecipadas. ${ }^{10} \mathrm{O}$ Parlamento do Reino Unido em 2005 aprovou o Ato de Capacidade Mental, que instrui sobre a vida das pessoas que perderam a capacidade mental e relaciona uma cadeia de temas direcionados às implicaçóes desta perda. Foi também proposto um código prático para este Ato que norteia o dia-a-dia das pessoas que cuidam e/ou são responsáveis por pacientes que perderem a capacidade mental. Estas açóes procuram estabelecer um protocolo de boa conduta para situaçóes que envolvem os que perderam a capacidade mental. ${ }^{11} \mathrm{O}$ código de prática adotado pela BMA avalia situaçóes baseadas num fluxograma que primariamente verifica a capacidade mental para se considerar o respeito a autonomia da pessoa que possui uma declaração de vontades antecipadas. Em caso de emergência, os tratamentos não podem ser retardados ou serem recusados se não houver uma indicação de validade da declaração de vontades antecipadas, conforme a aplicação do fluxograma.

\subsection{Espanha}

No ano 2000 foi aprovado, pelo parlamento da Catalunha, o projeto de lei que permitia a qualquer pessoa, por meio de vontade expressa, evitar certos tratamentos médicos em caso de sofrer enfermidade terminal. ${ }^{12}$ A Conferência Episcopal Pública, no mesmo ano, promoveu e lançou bases para uma proposta de Testamento Vital. Esta entidade eclesiástica fundamenta-se no dogma religioso de que a morte é inevitável e o fim da existência terrena abre os caminhos para os que têm fé a se juntarem a Deus. Ela defende que o testamento vital deve ser entendido como um pedido de ajuda do declarante para assumir, de forma cristã e humana, a própria morte. A Entidade entende que o documento ampara aqueles que evocam conscientemente essa responsabilidade, em face de uma enfermidade grave e incurável, que não se mantenha a vida por tratamentos

10 UNITED KINGDOM. Acts of the UK Parliament and Explanatory Notes. Disponível em: <http:// www.opsi.gov.uk/acts/acts2005/20050009.htm. Acesso em: 15 set. 2014.

11 Idem.

12 CONVENIO DEL CONSEJO DE EUROPA SOBRELOS DERECHOS DEL HOMBRE Y LA BIOMEDICINA DE 1997. Disponível em: <http://www.coe.int/t/dg2/trafficking/campaign/Source/ PDF_Conv_197_Trafficking_Spanish.pdf > ou http://www.bioeticas.net/leg/001.htm. Acesso em: 20 set. 2014. 
despropositados ou extraordinários, não se aplique a eutanásia ativa, não se prolongue a vida abusiva e irracionalmente frente ao processo de morte e que sejam administrados tratamentos paliativos para os sofrimentos. ${ }^{13}$

Outras províncias como a Galícia, Extremadura, Madrid, Aragon, Navarra, Catambria e Euzkadi aprovaram estatutos próprios que culminaram na Lei Básica reguladora da autonomia do paciente e dos direitos e obrigaçóes em matéria de informação e de documentação clínica publicada naquele país em 31 de outubro de 2002 - Lei 41/2002. A lei, que foi espelhada no mundo anglo-saxão, prevê o direito à autonomia e ao consentimento informado. A judicação da atividade médica favoreceu a chamada medicina defensiva. $\mathrm{O}$ processo de especialização e tecnificação da ciência médica somada à despersonalização na assistência à saúde desaguaram na exigência de resultados e responsabilidades valoradas economicamente. O empobrecimento da relação médico-paciente é um tributo promovido pela mudança de paradigma que tornaram a saúde um bem valorado na sociedade hodierna.

O código penal espanhol proíbe formalmente qualquer tipo de eutanásia (Art 134.4), embora, a contra senso, admita atenuantes para certas situaçóes. O testamento vital na Espanha ainda pode ser um instrumento perfeitamente útil para o ilícito tipificado entendido como eutanásia passiva e eutanásia ativa indireta na proteção do médico e dos Hospitais.

\subsection{Portugal}

Portugal ratificou a Convenção sobre os Direitos do Homem e a Biomedicina, o que implica no "dever de respeito pela vontade anteriormente manifestada pelo doente". O Testamento Vital ainda náo é assegurado por lei portuguesa. Segundo Rui Nunes, presidente da Associação Portuguesa de Bioética, existe a previsão legal, no código penal português no seu artigo 156. Em outubro de 2007, foi proposto aos deputados patrícios a criação de um Registro Nacional de Directivas Antecipadas de Vontade (Rendav), a ser implantado até 1 de Janeiro de 2008. A regulamentação tem como proposta "o exercício do direito a formular diretivas antecipadas de vontade no âmbito da prestação de cuidados de saúde" e estipula que o documento terá uma duração máxima de três anos, podendo ser alterado a qualquer momento. Assegura, ainda, aos profissionais de saúde o direito à objeção de consciência. Podem fazer um testamento as pessoas maiores de idade, que gozem de plena capacidade de exercício dos direitos e o consentimento deve ser livre e esclarecido. Deve ser assinado na presença de um notário, de um funcionário do "Rendav" ou de três testemunhas ${ }^{14}$.

13 Idem.

14 IN VERBIS: Revista Digital de Justiça e Sociedade. Portal Verbo Jurídico. [on line] Disponível em: <http://www.inverbis.net/actualidade/testamento-vital.html>. Acesso em: 20 nov. 2014. 


\subsection{Itália}

Segundo Massimo Donadi, porta-voz do partido Itália dos Valores, da coalizão governamental de centro-esquerda, os casos noticiados significam uma chamada aos legisladores para que "enfrentem a questão do Testamento Biológico". ${ }^{15} \mathrm{O}$ parlamento atualmente debate o tema para a definiçáo de um texto como projeto de lei, a fim de introduzir o Testamento Vital que garantirá os direitos dos médicos e dos pacientes. A ministra da Saúde, Lívia Turco, comentou que "não é aceitável a eutanásia", mas é "necessário respeitar a vontade do doente que náo quer ser curado"16.

O código de deontologia médica italiano prevê que o médico deve respeitar a vontade precedentemente expressa pelo paciente. A Itália, sendo um país de maioria católica, pôde vivenciar, em 2005, a vontade expressada pelo Papa João Paulo II nos seus últimos dias de vida.

\section{A Capacidade Humana de Testar}

$\mathrm{O}$ direito à personalidade enseja um conteúdo de grande relevância sendo muito mais vasto e importante do que comumente se considera. Há quem o tenha como um principio fundamental diretor, segundo o qual deve ser lido e interpretado todo o ordenamento jurídico brasileiro. Indiscutivelmente carrega, em seu bojo, toda carga principiológica basilar do Estado Democrático de direito, marcantemente a dignidade da pessoa humana, já que esse tem sua aplicabilidade no exercício dos direitos personalíssimos.

Para Maria Helena Diniz, direito da personalidade é o direito da pessoa de defender o que lhe é próprio, ou seja, a sua integridade física (vida, alimentos, o próprio corpo vivo ou morto, o corpo alheio vivo ou morto, partes separadas do corpo vivo ou morto), a sua integridade intelectual (liberdade de pensamento, autoria cientifica, artística e literária) e a sua integridade moral (honra, recato, segredo pessoal, profissional e domestico, imagem, identidade pessoal, familiar e social). ${ }^{17}$ Segundo Gofredo Telles Jr., é o direito comum da existência, porque é simples permissão dada pela norma jurídica, a cada pessoa, de defender um bem que a natureza lhe deu, de maneira primordial e direta.

Deste modo, é do direito da personalidade que decorre o direito de testar. Inquestionavelmente, o direito ao testamento vital retira seu fundamento, ou razáo de ser, do

15 CLICABRASÍLIA.COM.BR. Morte por greve de fome de doente que pedia eutanásia reabre debate na Itália. Disponível em: http://www.clicabrasilia.com.br/portal/noticia_new. php?IdNoticia=3313224/07/2007. Acesso em: 15 set. 2014.

16 JORNAL DO BRASIL. Morte por greve de fome de doente que pedia eutanásia reabre debate. Agência EFE; 2007. Disponível em:<http://jbonline.terra.com.br/extra/2007/07/24/e240711824.html>. Acesso em 20 nov. 2014.

17 DINIZ, Maria Helena. O estado atual do biodireito, Editora Saraiva, São Paulo, 2006. 
direito da personalidade, como já afirmado, não se pode olvidar que os direitos e garantias individuais plasmados na Carta Magna decorrem do direito da personalidade, ainda que eventualmente materializados por meio de alguma das suas manifestaçóes como o direito à dignidade da pessoa humana, o direito à intimidade, o direito à liberdade, o direito à integridade física.

O testamento público, conforme leciona Argentino I. Néri, é uma das tantas instituições jurídicas legadas pelos romanos, tendo-se chegado à forma pública, primeiro, pelo testamentum apud acta conditum, através de declaração verbal feita ante autoridades judiciais, e, em seguida, pelo testamentum principi oblatum, mediante a entrega das disposiçóes, por escrito, ao imperador, para sua guarda em arquivo.

No direito pátrio, em período anterior ao Código Civil de 1916, já havia previsão do testamento público, nas Ordenaçóes do Reino de Portugal, as quais denominavam-no testamento aberto.

O testamento público é aquele testamento feito pelo tabelião, em seu livro de notas, perante o testador e duas testemunhas, em atendimento à vontade inequívoca manifestada pelo testador e observada a solenidade determinada pela lei. No dizer de Itabaiana de Oliveira, testamento público "é aquele que é feito em livro de notas, escrito pelo oficial público com funçôes de tabelião, de acordo com as declarações do testador, exaradas verbalmente" ${ }^{18}$

Para Sílvio de Salvo Venosa ${ }^{19}$, é o "ato aberto, no qual um oficial público exara a última vontade do testador, conforme seu ditado ou suas declaraçóes espontâneas, na presença de $[. .$.$] duas testemunhas".$

Clóvis Bevilácqua conceituou-o como sendo o testamento "escripto por official publico em seu livro de notas, contendo a declaração da ultima vontade do testador, feita perante o mesmo official e cinco ${ }^{20}$ testemunas idôneas". ${ }^{21}$ Tal conceito encontrou severas críticas por ensejar somente um conteúdo objetivamente patrimonial.

Bem andou o legislador ao inserir, no Código Civil de 2002, a admissão de que o testamento tenha conteúdo não patrimonial, a exemplo do que se ver do artigo $1.857, \$$ $2^{\circ}$, como se dá no caso de instituição de bem de família voluntário (art. 1.711 do CC).

A respeito da possibilidade de conter o testamento público conteúdo não-patrimonial, interessante passagem traz Pontes de Miranda: "No período da Reconquista,

18 Ibid, p. 434.

19 VENOSA, Silvio de Salvo. Direito Civil, Direito das Sucessóes, 3 ed. São Paulo: Atlas, 2005, p. 161

20 Novo Código Civil de 2002, são necessárias duas testemunhas, e não as cinco exigidas pelo Código anterior.

21 Código Civil dos Estados Unidos do Brasil, v. 2, p. 829. 
testamento, em Portugal, era mais para o bem da alma do que para outro fim [...]" ${ }^{22}$ No mesmo sentido leciona Justino Adriano Farias da Silva, ao asseverar que, no século XII, o testamento "deixa de ser um ato de direito privado que se preocupa, fundamentalmente, com a sucessão dos bens do falecido. Constitui-se, antes de mais nada, um ato religioso de uso quase obrigatório. Não testar acarretava a pena de excomunhão e não poderia ser o defunto sepultado nem na Igreja nem no cemitério". ${ }^{23}$

É de importância ímpar e, notadamente o objeto de todos os testamentos, incluindo-se aí o testamento público, é a da capacidade testamentária, ativa e passiva, isto é, a análise de quem pode testar, e que pode ser beneficiado em testamento.

A capacidade testamentária ativa determina as pessoas que podem testar. Trata-se de capacidade especial para testar, a qual não se confunde com a capacidade geral, para os atos da vida civil. A matéria encontra-se tratada no artigo 1.860 do Código Civil. Como negócio jurídico que é o testamento exige, para sua validade, agente capaz.

Têm capacidade testamentária ativa todas as pessoas naturais que a lei não declare incapazes de testar. As pessoas jurídicas, ao contrário, não a têm.

Tem a capacidade testamentária ativa o condão de permitir que somente aqueles que têm condiçóes de entender e de querer, que tem pleno discernimento para entender a extensão do ato que está praticando e manifestar segura e livremente a sua vontade, possam fazer um testamento. Eis a razão pela qual o caput do artigo 1.860 do Código Civil limita-se a afirmar que não poderão testar os incapazes e os que não tiverem pleno discernimento no momento do ato de testar.

Em primeiro lugar, estão impossibilitados de testar os absoluta e relativamente incapazes, previstos nos artigos $3^{\circ}$ e $4^{\circ}$ do Código Civil, e o estão na exata medida do óbice para os demais atos da vida civil. Isto significa dizer que os absolutamente incapazes jamais poderão testar, todavia, no que concerne aos relativamente incapazes, necessário se faz uma análise mais aguçada do caso. As situaçôes previstas nos incisos II e III do artigo $4^{\circ}$ do Código Civil exigem um grau de análise a respeito do nível de incapacidade gerado pelas hipóteses ali estipuladas. Se a pessoa estiver interditada, não haverá maiores dúvidas, porquanto os limites da incapacidade estarão definidos pelo juiz, na sentença (artigo 1.772 do Código Civil). Todavia, diante da inexistência de interdição, deverá haver uma análise que possa estabelecer os limites da incapacidade natural ${ }^{24}$ - incapacidade de entender e de querer - gerada, a fim de se estabelecer se há ou não capacidade para o ato

22 PONTES DE MIRANDA, Francisco Cavalcanti. Tratado de direito privado. 2. ed. Rio de Janeiro: Borsoi, 1969 , t. 59, $\$ 5.864$.

23 SILVA, Justino Adriano Farias da. Tratado de direito funerário. São Paulo: Método Editora, 2000 , t. I, p.608.

24 GOMES, Orlando. Introduçáo ao direito civil. 18. ed. Rio de Janeiro: Forense, 2001, p. 171. 
específico, isto é, a fim de estabelecer se a pessoa tem ou não condiçôes de entender o ato que está praticando. Tal análise vale no que toca a todos os atos da vida civil, e também ao testamento.

No concernente ao pródigo, entendem alguns que pode ele testar, sob a alegação de que elaborar testamento não se encontra dentre os atos que lhe são vedados (artigo 1.782 do Código Civil), ${ }^{25}$ o que não parece a melhor solução, uma vez que o testamento é ato de alienaçáo para depois da morte, através do qual alguém dispóe de seus bens para após a sua morte, ultrapassando a margem dos atos de simples administração, encontrandose, portanto, dentre os atos vedados ao pródigo, e constantes no artigo 1.782 do Código Civil. Permitir ao pródigo testar, seria permitir o que se lhe quer vedar: dilapidar o seu patrimônio, ainda que com eficácia posterior à sua morte.

Qualquer pessoa, enfim, que não tenha pleno discernimento para o ato, que não tenha condiçôes de entender o ato em todo o seu alcance, não poderá testar, por lhe faltar capacidade jurídica para o ato.

É de notar-se que a idade avançada ou enfermidade grave não extirparão da pessoa a sua capacidade testamentária ativa, desde que continue ela no pleno gozo de suas faculdades mentais.

Cumpre assinalar que o parágrafo único do artigo 1.860 do Código Civil confere capacidade testamentária aos maiores de dezesseis anos. Tais pessoas, ordinariamente são consideradas relativamente incapazes, por força do artigo $4^{\circ}$ do Código Civil, devendo ser assistidos nos atos da vida civil. Porém, no testamento, têm eles plena capacidade, não havendo necessidade de assistência para o ato.

Importante assinalar, por fim, no que tange a capacidade testamentária ativa, que ela é determinada no momento da realização do testamento. A superveniência de capacidade para quem era incapaz no momento da realização do testamento não valida o ato, da mesma forma que a superveniente incapacidade para quem era capaz, não invalida o ato feito.

Já no que concerne à capacidade testamentária passiva, determina ela a capacidade de ser instituído herdeiro ou legatário em testamento. Em regra, possui capacidade testamentária passiva qualquer pessoa, natural ou jurídica, brasileira ou estrangeira, existente ao tempo da morte do testador (artigo 1.798 do Código Civil). Todavia, embora essa seja a regra, algumas exceçôes despontam.

25 BARROS, Flávio Augusto Monteiro de. Direito das sucessôes. São Paulo: Curso Preparatório para Concursos, 2003, p. 54, e MONTEIRO, Washington de Barros. Curso de direito civil: direito das sucessóes. 35 ed. Atualizado por Ana Cristina de Barros Monteiro França Pinto. Sáo Paulo: Saraiva, 2003. v. 6, p. 129. 
Em primeiro lugar, como exceção à regra, surgem algumas situaçóes de pessoas que têm capacidade testamentária passiva sem que, contudo, existam ao tempo da morte do testador. São o nascituro, a prole eventual, a fundação e a pessoa jurídica sem registro.

$\mathrm{O}$ nascituro tem seus direitos assegurados desde a concepção (artigo $2^{\circ}$ do Código Civil) e, nascendo com vida, será o titular de tais direitos. Assim, se quando da morte do testador estiver concebido o nascituro, seus direitos hereditários estarão assegurados e, havendo o nascimento com vida, receberá a herança ou o legado (artigo 1.798 do Código Civil).

\section{0 Leading Case: Ministério Público do Estado do Rio Grande do Sul versus João Carlos Ferreira}

Um caso bastante ilustrativo da potencialidade de novas reflexôes e repercussão do tema do testamento vital é o leading case que envolve um pedido de alvará judicial do Ministério Público do Estado do Rio Grande do Sul para suprimento de vontade do idoso João Carlos Ferreira, que tramitou, em grau de apelação, perante o Tribunal de Justiça do Estado do Rio Grande do Sul (autuado sob o número 0223453-79.2013.8.21.7000). ${ }^{26}$

O pedido se referia à supressão de vontade do idoso (usuário-morador do Hospital Colônia Itapuã e ex-hanseniano) em questáo no que se referia à necessidade de amputação do membro inferior esquerdo, em razão da necrose detectada no pé esquerdo, decorrente de uma lesão sofrida.

Segundo a decisão, a necrose já estava acarretando o emagrecimento progressivo, anemia acentuada e, se não fosse realizado o tratamento em referência, a morte se daria em consequência de infecção generalizada.

O julgado noticiava ainda que o idoso não apresentava sinais de demência, mas se encontrava em estado depressivo, razão pela qual manifestava a desistência em relação à vida e enxergava na morte uma forma de alívio do sofrimento.

O juízo singular negou o citado pedido de alvará judicial, pois entendia que o idoso já suportava a doença há muito tempo, além de não verificar nele a perda de sua capacidade civil, de forma que se encontrava no pleno gozo da liberdade para agir e, justamente por esse motivo, não cabia ao Estado a interferência em sua decisão, ainda que o resultado morte pudesse ser concretizado.

Na decisão, firmou-se a distinção entre:

26 TRIBUNAL DE JUSTIÇA DO ESTADO DO RIO GRANDE DO SUL. Apelação no $\mathbf{0 2 2 3 4 5 3 -}$ 79.2013.8.21.7000. Rel. Des. Irineu Marini. Disponível em <www.tj.rs.jus.br>. Acesso em 14 mai 2015 . 
a) a eutanásia (também conhecida como boa morte, morte apropriada, suicídio assistido, crime caritativo ou morte piedosa), na qual uma pessoa solicita ao médico ou a um terceiro que o mate, com o fito de que sejam eliminados os males de uma moléstia;

b) a ortotanásia, que "vem a ser a morte no seu devido tempo, sem prolongar o sofrimento, morte sem prolongar a vida por meios artificiais ou além do que seria o processo natural" 27 ; e

c) a distanásia (alcunhada também como obstinação terapêutica ou futilidade médica), segundo a qual todos os tratamentos médicos devem ser impostos a um paciente, ainda que estes não surtam qualquer resultado proveito ou implique em sofrimento atroz ao paciente terminal, a qual, ao invés de prolongar a vida do paciente, acaba por alongar o processo de morte.

A aludida Corte entendeu que a demanda representava o caso da ortonásia, a qual seria permitida pelas Resoluçóes do Conselho Federal de Medicina de número 1.805/2006 e $1995 / 2012$.

Em seu fundamento, a decisão cita até mesmo a Encíclica Evangelium Vitae, que foi promulgada, em 1995, pelo Papa João Paulo II. Esse documento condena apenas a eutanásia e a distanásia, razão pela qual a ortonásia seria tolerada pela religião católica.

Ademais, outro fundamento interessante é de que o direito à vida (inscrito na Constituição da República Federativa do Brasil, em seu artigo 50) não é absoluto e deve ser lido em consonância com o princípio da dignidade da pessoa humana (previsto no artigo 2º, III do mesmo Diploma normativo).

Chega-se, portanto, à conclusão de que a ordem constitucional brasileira assegura o direito à vida e não impóe um dever à vida, razão pela qual foi assegurada indiretamente ao paciente a liberdade de não se submeter ao tratamento que lhe causaria sofrimento de ordem moral.

Reforça, ainda, a decisão a previsão contida no artigo 15 do Código Civil, na qual resta consignado que ninguém deve ser submetido, com risco de vida, à tratamento médico ou intervenção cirúrgica.

O caso deve ser entendido como paradigmático especificamente porque cita explicitamente a figura do instituto do "testamento vital", que estaria previsto na Resolução no 1995/2012 do Conselho Federal de Medicina, que necessitaria conjugar os seguintes requisitos: a) decisão antecipada do paciente em relação à fase crítica da moléstia;

27 Idem. 
b) paciente em plenas condiçóes de consciência; e c) prevalência da vontade do paciente em determino daquela externada pelos seus familiares e pela sua equipe médica.

\section{Conclusões}

O testamento vital não se encontra contemplado em nossa legislação, mas como já visto o testamento vital assim como o testamento comum, retira seu fundamento no intitulado direito da personalidade - direito cardeal - e extremamente abrangente - podendo deduzir-se que se encontra uma face da mesma moeda.

No ínterim da Bioética e do Direito ante as atuais concepçóes jurídicas sobre a proteção da vida e a postura judaico-cristã sobre a qual se erigiu nossa nação, nos leva a questionar sob quais argumentos poríamos erigir a prática socialmente aceita e juridicamente aplicável o futuro instituto do Testamento vital.

É imperativo se ter em mente a construção de um modelo que possa ser utilizado implica no estabelecimento de fundamentos focados na filosofia, na Bioética e nos conflitos judiciais, mas também antes de toda a problemática ensejada no campo das ciência humanas, não há de se ignorar as atuais tempos de ciência e tecnologia capazes de realizar prognósticos seguros que permitam uso do, futuramente implantado, testamento vital, com segurança para toda a sociedade. Não se deve aplicar ao Testamento Biológico um caráter reducionista de "livre escolha" de suportes de apoio vital relacionados à assistência médica, mas sim respaldar e prover informaçóes que esclareçam as possibilidades de escolha em caso de eventos que se instalem num processo de terminalidade.

Desse modo, ainda que não faça parte ainda do direito positivo brasileiro, não podemos considerar impossível que este possa vir a existir dentro de nosso ordenamento. Tampouco se deve entender o testamento vital mero direito alternativo ou insurgente - na acepção de que se privilegia determinado valor para considerar jurídico algum comportamento realizado às testilhas da lei - a despeito da falta de previsão legal, pois, como já anteriormente dito, é um direito que decorre do direito da personalidade que tem fundamentos e garantias constitucionais.

Realmente, a literatura jurídica atinente a testamento vital é extremamente escassa e o tema não tem merecido a devida atenção da comunidade jurídica, apesar da sua inegável atualidade, onde o significativo e veloz avanço da tecnologia, particularmente ligado à medicina, tem proporcionado expressiva postergação da morte - como é notório, hoje em dia são inúmeros os recursos tecnológicos que proporcionam o prolongamento artificial da vida, muitas vezes independentemente da aquiescência do paciente com tal situação que, sem dúvida alguma, além de não gozar a vida, muito provavelmente padece de terríveis sofrimentos, certamente injustificáveis se considerado que, de forma invariável, esse tipo de vida fictícia tem se revelado irreversível. 
O testamento vital seria um documento em que a pessoa determina, de forma escrita, que tipo de tratamento ou não tratamento deseja para a ocasião em que se encontrar doente, em estado incurável ou terminal e incapaz de manifestar sua vontade.

Logo, não se confunde testamento vital com o chamado consentimento informado tendo em conta que este "é mais necessário quanto menos urgente é o tratamento e quanto mais experimental, pelo que tem seu campo limitado às situaçôes programadas ou não emergenciais, onde é possível o paciente ou enfermo exteriorizar sua concordância com determinado tratamento. Ao contrário, o testamento vital vai muito além de mera concordância ou consentimento com determinado tratamento (experimental ou não), mas significa verdadeiro ato de disposição ou estabelecimento - praticamente uma ordem - do tipo de procedimento que devera ser realizado para o caso extremo de enfermidade, incurável ou terminal, que implique manutenção da vida de forma artificial e por período incerto, ainda que não envolva significativa dor ou sofrimento, conferindo outro caráter a relação médico-paciente.

À evidência, o testamento vital encerra importantíssimo ato de vontade, derivado, pois, do direito da personalidade, que exige certos requisitos:

a) capacidade civil do testador;

b) materialização através de documento escrito;

c) objetos ou termos induvidosos e não dúbios;

d) subscrição de duas testemunhas.

Como testamento que é, o testamento vital obviamente é ato personalíssimo, só pode emanar inexoravelmente, da vontade do testador, unilateral, em que náo existe contraparte ou aceitante da manifestação da última vontade e pode ser mudado ou revogado a qualquer tempo.

Entretanto, é imperioso notar que, consoante à legislação penal vigente, ao cumprir as disposiçôes insertas num testamento vital o agente incorrerá em crime. Assim é que, conforme a natureza da atitude ou comportamento do agente, configurar-se-á o crime de homicídio privilegiado por motivo de relevante valor social ou moral (artigo 121, parágrafo $1^{\circ}$ do Código Penal), necessariamente através de ato comissivo, ou crime de auxilio ao suicídio (artigo 122 caput do Código Penal), obrigatoriamente por meio de ato omissivo, considerando que ainda não há, no direito positivo brasileiro, a previsão legal (proibitiva ou permissiva) da controvertida figura da eutanásia, distanásia e ortotanásia.

Notou-se, ainda, diante do leading case brasileiro, que há a possibilidade de se admitir o testamento vital em relação à ortotanásia, especialmente quando conjugados os requisitos contidos na Resolução no 1995/2012 do Conselho Federal de Medicina, quais sejam: a) decisão antecipada do paciente em relação à fase crítica da moléstia; b) paciente 
em plenas condiçóes de consciência; e c) prevalência da vontade do paciente em determino daquela externada pelos seus familiares e pela sua equipe médica.

É importante se ter em mente que a vida encontra-se assegurada, no bojo do texto da Constituição da República Federativa do Brasil, como um direito e não como um dever, bem como que a sua leitura e compreensão precisa estar com o princípio da dignidade da pessoa humana.

Espera-se que o presente artigo possa suscitar novas reflexôes em relação à temática envolvida, especialmente para que seja ele bem compreendido e que sejam notadas as suas efetivas possibilidades, inclusive no cenário jurídico brasileiro, onde paira sempre uma nuvem de insegurança em relação à falaciosa percepção de que o direito à vida se repousaria na condição de um direito absoluto e invencível.

\section{Referências}

BARROS, Flávio Augusto Monteiro de. Direito das sucessóes. São Paulo: Curso Preparatório para Concursos, 2003.

BBC. A Short History of Important Events; 2006. Disponível em: <http://www.bbc. co.uk/religion/ethics/euthanasia/overview/livingwills_print.html. Acesso em: 13 out. 2014.

BORGES, Roxana Cardoso Brasileiro. Direito de morrer dignamente: eutanásia, ortotanásia, consentimento informado, testamento vital, análise constitucional e penal e direito comparado. In: Santos MCCL (org.). Biodireito: ciência da vida, os novos desafios.[2001]. Disponível em: <http://jus2.uol.com.br/doutrina/texto. asp?id=7571. Acesso em: 10 out. 2014.

. Direito de morrer dignamente: eutanásia, ortotanásia, consentimento informado, testamento vital, análise constitucional e penal e direito comparado. In: SANTOS, Maria Celeste Cordeiro Leite dos (org.). Biodireito: ciência da vida, os novos desafios. São Paulo: RT, 2001.

CALVO, Adriana Carrera SANTOS, Maria Celeste Cordeiro Leite dos (org.). Biodireito: ciência da vida, os novos desafios. São Paulo: RT, 2001.

CENTRAL NOTTINGHAMSHIRE HEALTH COMMUNITY. 2005. Disponível em:<http://www.nimhe.csip.org.uk/silo/files/livingwillspdf.pdf. Acesso em: 23 set. 2014.

CLICABRASÍLIA.COM.BR. Morte por greve de fome de doente que pedia eutanásia reabre debate na Itália. Disponível em: http:/www.clicabrasilia.com.br/portal/noticia_new.php?IdNoticia=3313224/07/2007. Acesso em: 15 set. 2014. 
CONVENIO DEL CONSEJO DE EUROPA SOBRELOS DERECHOS DEL HOMBRE Y LA BIOMEDICINA DE 1997. Disponível em: <http://www.coe. int/t/dg2/trafficking/campaign/Source/PDF_Conv_197_Trafficking_Spanish.pdf> ou http://www.bioeticas.net/leg/001.htm. Acesso em: 20 set. 2014.

CORDEIRO, Maria Celste apud PESSINI, L. Distanásia. Até quando prolongar a vida? São Paulo: Centro Universitário São Camilo e Ediçóes Loyola, 2001.

DINIZ, Maria Helena. O estado atual do biodireito, Editora Saraiva, São Paulo, 2006.

FERRY, Luc. Aprender a viver: filosofia para novos tempos. Trad. Véra Lúcia dos Reis. Rio de Janeiro: Objectiva, 2007.

FRANÇA, GV. Comentários ao Código de Ética Médica. São Paulo: Saraiva, 1997.

GOMES, Orlando. Introduçáo ao direito civil. 18. ed. Rio de Janeiro: Forense, 2001.

IN VERBIS: Revista Digital de Justiça e Sociedade. Portal Verbo Jurídico. [on line] Disponível em: <http://www.inverbis.net/actualidade/testamento-vital.html>. Acesso em: 20 nov. 2014.

JORNAL DO BRASIL. Morte por greve de fome de doente que pedia eutanásia reabre debate. Agência EFE; 2007. Disponível em:<http://jbonline.terra.com.br/extra/2007/07/24/e240711824.html>.Acesso em 20 nov. 2014.

KUTNER apud RIBEIRO, Diaulas Costa. Suspensão de esforço terapêutico. Cadernos de direito clínico. Faculdade de Ciências Jurídicas do Planalto Central. Ano I, número 1, Out. 2005. Brasília.

MONTEIRO, Washington de Barros. Curso de direito civil: direito das sucessóes. 35 ed. Atualizado por Ana Cristina de Barros Monteiro França Pinto. São Paulo: Saraiva, 2003.

PONTES DE MIRANDA, Francisco Cavalcanti. Tratado de direito privado. 2. ed. Rio de Janeiro: Borsoi, 1969.

RIBEIRO, Diaulas Costa. Suspensão de esforço terapêutico. Cadernos de direito clínico. Faculdade de Ciências Jurídicas do Planalto Central. Ano I, número 1, Out. 2005. Brasília.

SILVA, Justino Adriano Farias da. Tratado de direito funerário. São Paulo: Método Editora, 2000.

TRIBUNAL DE JUSTIÇA DO ESTADO DO RIO GRANDE DO SUL. Apelaçáo no 0223453-79.2013.8.21.7000. Rel. Des. Irineu Marini. Disponível em <www.tj.rs. jus.br>. Acesso em 14 mai 2015. 
UNITED KIGNDOM. Acts of the UK Parliament and Explanatory Notes; 2005. Disponível em: <http://www.opsi.gov.uk/acts/acts2005/20050009.htm. Acesso em: 15 set. 2014.

VENOSA, Silvio de Salvo. Direito Civil, Direito das Sucessóes, 3 ed. São Paulo: Atlas, 2005. 